\title{
Gastric bypass surgery alters the mechanisms of insulin resistance in the adipose tissue of GK rats
}

\author{
JIBIN LI, YONG WANG, YONG ZHOU and JINGANG LIU \\ Department of General Surgery, Shengjing Hospital, China Medical University, Shenyang 110004, P.R. China
}

Received April 10, 2012; Accepted August 13, 2012

DOI: $10.3892 / \mathrm{mmr} .2012 .1053$

\begin{abstract}
Roux-en-Y gastric bypass (RYGB) has become an effective treatment for type 2 diabetes mellitus (T2DM). However, the blood glucose mechanism involved remains unclear. In this study, 60 male Goto-Kakizaki (GK) rats were randomly divided into 6 groups (each with 10 rats): the GB1/2 group (treated with gastric bypass surgery), the SO1/2 group (treated with sham operation) and the CO1/2 group (with normal water consumption only). We tested expression levels of tumor necrosis factor $\alpha(\mathrm{TNF} \alpha) \mathrm{mRNA}$, glucose transporter 4 (GLUT4), peroxisome proliferator-activated receptor $\gamma 2$ (PPAR $\gamma 2)$ and phosphatidylinositol-3-kinase subunit $\mathrm{p} 85 \alpha(\mathrm{PI} 3 \mathrm{Kp} 85 \alpha)$ in the adipose tissues. We found that the weight, fasting blood glucose and postprandial blood glucose decreased in the GB group compared with the CO group. A total of 20 and 30 days after surgery, PPAR $\gamma 2$, PI3Kp85 $\alpha$ and GLUT4 increased in the fat tissue in the GB group compared with the $\mathrm{CO}$ group. However, 20 days after surgery, TNF $\alpha$ mRNA decreased in fat tissue by 0.51 times in the GB group compared with the CO group, and serum TNFa levels showed no statistically significant difference. Fasting blood glucose and GLUT4 membrane protein were negatively correlated. In conclusion, RYGB may improve insulin resistance and treat T2DM through upregulation of the PPAR $\gamma 2$ protein, downregulation of $\mathrm{TNF} \alpha$ mRNA transcription, through the autocrine pathway, upregulation of PI3Kp $85 \alpha$ expression, upregulation of GLUT4 mRNA transcripts and by inducing translocation of GLUT4 in adipose tissue.
\end{abstract}

\section{Introduction}

It has been reported that the incidence of diabetes has increased to up to $9.7 \%$ of the population over the age of 20 in China (almost 92.4 million in total) (1). Globally, China has become the country with the fastest growth in diabetes incidence, overtaking India. Type 2 diabetes mellitus (T2DM) patients account

Correspondence to: Dr Jingang Liu, Department of General Surgery, Shengjing Hospital, China Medical University, 36 Sanhao Street, Shenyang 110004, P.R. China

E-mail: cmu2h_ljg@163.com

Key words: gastric bypass surgery, type 2 diabetes, TNFa, GLUT4 for $90 \%$ of all patients with diabetes, and the number of diabetes patients overall has increased primarily due to the increase in T2DM patients. Over the years, the clinical treatment of T2DM has involved using traditional conservative therapy, including drugs to stimulate insulin secretion and insulin replacement therapy. However, according to a recent study, drug therapy and insulin replacement therapy cannot delay the complications in high-risk T2DM patients and cannot improve the prognosis (2). A weight-loss surgeon discovered coincidentally that the blood glucose in obese Roux-en-Y gastric bypass (RYGB) patients with T2DM decreased to normal levels postoperatively and was maintained in the long-term (3). Currently, as the medical treatment of T2DM and control of complications is generally ineffective, this discovery will undoubtedly bring a glimmer of hope for the majority of T2DM patients.

The main clinical manifestations of T2DM include damaged islet cell function and progressive increases of insulin resistance (4). In the pathogenesis of T2DM, insulin resistance is an important link, which is mainly caused by decreasing the glucose uptake and use of the peripheral tissues. In the course of peripheral tissue glucose utilization, the transmembrane transport of glucose, which is mediated by glucose transporter 4 (GLUT4), is the main rate-limiting step.

Certain studies have shown that peroxisome proliferatoractivated receptor $\gamma 2$ (PPAR $\gamma 2)$, tumor necrosis factor $\alpha$ $(\mathrm{TNF} \alpha)$ and GLUT4 are closely related to insulin resistance (5-8). The expression of serum TNFa in patients with T2DM was upregulated significantly $(9,10)$. Upregulation of GLUT4 may improve insulin resistance, while downregulation of GLUT4 expression may induce or exacerbate insulin resistance $(11,12)$.

Currently, the mechanism of RYGB in the treatment of T2DM has become an international hotspot for research. However, its exact mechanism remains unclear. In this study, we supposed that RYGB may improve blood glucose through regulating certain fat factors and glucose transporter proteins. Therefore, investigating the changes in PPAR $\gamma 2, \mathrm{TNF} \alpha$, phosphatidylinositol-3-kinase subunit p85 $\alpha$ (PI3Kp85 $\alpha)$ and GLUT4 expression following RYGB surgery is essential in order to reveal the mechanism involved.

\section{Materials and methods}

Animal grouping. The experimental animals [8-week-old Goto-Kakizaki (GK) rats] were all purchased from SLAC, Ltd. 
(Shanghai, China). When the 60 male GK rats were adapted to the environment after two weeks, they were randomly divided into 6 groups $(\mathrm{n}=10)$. The surgery group 1 (GB1), sham operation group 1 (SO1) and control group 1 (CO1) were monitored 20 days after RYGB surgery, while GB2, $\mathrm{SO} 2$ and $\mathrm{CO} 2$ were monitored 30 days after RYGB surgery. The animals were housed in a SPF animal experiment center in Shengjing Hospital of China Medical University, and the feeding conditions were as follows: a normal day-and-night cycle, temperature $25 \pm 1^{\circ} \mathrm{C}$, relative humidity $45 \pm 2 \%$, with free access to water. The animal studies were agreed with the China Medical University Animal Research Committee.

Modeling. The GK rats underwent a 12-h fast and 4-h water deprivation prior to surgery and then were anesthetized with $10 \%$ chloral hydrate $(3 \mathrm{ml} / 100 \mathrm{~g}$ intraperitoneal injection). We performed a $2.5-\mathrm{cm}$ long incision in the middle upper abdomen. Gastric bypass surgery was performed in the surgery groups, in which approximately $10 \%$ of the stomach was kept at the end and the rest was removed, then the far end was closed. The jejunum was cut off $10 \mathrm{~cm}$ from the Treitz ligaments, and the distal intestinal loop lined residual gastrojejunostomy. End-to-side anastomosis was performed $10 \mathrm{~cm}$ away from the anastomosis at the proximal bowel and jejunum. In the sham groups, the cutting and in-situ anastomosis was performed using the equivalent anesthesia method and position, with the gastrointestinal tract anatomy unchanged. A similar surgical procedure was performed to ensure the same length of time, and consistency with $0 / 7$ thread. The abdominal cavity was flushed by a $3 \mathrm{ml}$ solution with 800,000 units penicillin. Free access to water was provided after the rats regained consciousness from anesthesia and free food after $24 \mathrm{~h}$. Free access to water was provided in the control group.

Western blotting. Total protein from cells was extracted in lysis buffer and quantified using the Bradford method. In total, $50 \mu \mathrm{g}$ of protein was separated by SDS-PAGE (12\%). After transferring to polyvinylidene fluoride (PVDF) membranes (Millipore, Billerica, MA, USA), the membranes were incubated overnight at $4^{\circ} \mathrm{C}$ with antibodies against PPAR $\gamma 2$, PI3Kp $85 \alpha$ and GLUT4 (1:1000; Abcam, Ltd., MA, USA). Following incubation with peroxidase-coupled anti-mouse IgG (Santa Cruz Biotechnology Inc., Santa Cruz, CA, USA) at $37^{\circ} \mathrm{C}$ for $2 \mathrm{~h}$, bound proteins were visualized using ECL (Pierce Biotechnology, Rockford, IL, USA) and detected using Bio Imaging Systems (UVP Inc., Upland, CA, USA). The relative protein levels were calculated based on $\beta$-actin protein as a loading control. The experiments were repeated 3 times independently.

Real-time PCR. Expression of TNF $\alpha$, PI3Kp85 $\alpha$ and GLUT4 mRNA were assayed using the TaqMan assay according to the manufacturer's instructions (Applied Biosystems, Foster City, CA, USA). Specific RT primers and TaqMan probes were used to quantify the expression of TNF- $\alpha$, PI3Kp $85 \alpha$ and GLUT4. For quantification of cell samples, RT-PCR analysis was performed in three independent experiments, each using three independent samples.

Statistical methods. The experimental data were expressed as the means \pm standard deviation and statistics were analyzed using SPSS 13.0 for Windows software. A t-test was used to compare the weight change prior to and following surgery. The single-factor analysis of variance was used to compare the change between groups and within the groups. The linear correlation analysis was used to compare the correlation between two indicators. $\mathrm{P}<0.05$ was considered to indicate a statistically significant difference.

\section{Results}

Body weight and blood glucose decreased following RYGB surgery. Twenty and 30 days after RYGB, the body weight of the rats decreased to $247.54 \pm 4.44 \mathrm{~g}$ and $244.54 \pm 3.48 \mathrm{~g}$, respectively. The loss of weight was approximately $10 \%$, and the difference was statistically significant when compared with the preoperative weight $(\mathrm{P}<0.01)$. However, the difference of body weight in the GB1 and GB2 groups was relatively stable and showed no significant difference $(\mathrm{P}>0.05)$. The weight in the GB group decreased significantly compared with the SO and $\mathrm{CO}$ groups, and the difference was statistically significant $(\mathrm{P}<0.01)$. The concentration of fasting and postprandial 2-h blood glucose in the GB group decreased significantly as compared to the $\mathrm{SO}$ and $\mathrm{CO}$ groups, and the difference was statistically significant $(\mathrm{P}<0.01)$. The blood glucose levels continued to decline at 20 days post-operation, but the difference was not statistically significant when compared with that in the 30 days post-operation group $(\mathrm{P}>0.05)$. The serum $\mathrm{TNF} \alpha$ after 20 and 30 days showed no significant difference, and was almost equal between the GB, SO and $\mathrm{CO}$ groups (Table I).

PPAR 2 protein expression increased following $R Y G B$ surgery. A total of 20 days after RYGB surgery, the PPAR $\gamma 2$ protein expression was increased by 1.36 times as compared to the $\mathrm{CO}$ group and the difference was statistically significant $(\mathrm{P}<0.01)$. Thirty days after surgery, the PPAR $\gamma 2$ protein expression was increased by 1.35 times and the difference was also significant $(\mathrm{P}<0.01)$. The PPAR $\gamma 2$ protein expression between the $\mathrm{SO}$ and $\mathrm{CO}$ groups showed no statistical significance $(\mathrm{P}>0.05)$. The PPAR $\gamma 2$ protein expression also showed no significant difference between the GB1 and GB2 groups ( $\mathrm{P}>0.05$; Fig. 1).

$T N F a$ mRNA expression decreased following RYGB surgery. A total of 20 days after surgery, the TNF $\alpha$ mRNA expression was decreased by 0.51 times as compared to the $\mathrm{CO}$ group and the difference was statistically significant $(\mathrm{P}<0.01)$. A total of 30 days after surgery, TNF $\alpha$ mRNA expression was decreased by 0.42 times as compared to the $\mathrm{CO}$ group and the difference was also statistically significant $(\mathrm{P}<0.01)$. The $\mathrm{TNF} \alpha \mathrm{mRNA}$ expression between the SO and $\mathrm{CO}$ groups was not statistically significant $(\mathrm{P}>0.05)$. The TNFa mRNA expression was also not significant between the GB1 and GB2 groups ( $\mathrm{P}>0.05$; Fig. 2).

PI3Kp $85 \alpha$ mRNA and protein expression increased following RYGB surgery. A total of 20 days after surgery, PI3Kp $85 \alpha$ mRNA expression was increased by 1.89 times as compared to the $\mathrm{CO}$ group and the difference was statistically significant $(\mathrm{P}<0.01)$. A total of 30 days after surgery, PI3Kp85 $\alpha$ mRNA 
Table I. Comparison of body weight, blood glucose and TNF $\alpha$.

\begin{tabular}{|c|c|c|c|c|c|}
\hline \multirow[b]{2}{*}{ Groups } & \multicolumn{2}{|c|}{ Body weight (g) } & \multicolumn{3}{|c|}{ Blood glucose } \\
\hline & Pre-operation & Post-operation & Fasting & 2-hour & $\mathrm{TNF} \alpha$ \\
\hline $\mathrm{CO} 1$ & $273.8 \pm 3.83$ & $273.27 \pm 2.89$ & $11.2 \pm 1.03$ & $22.1 \pm 1.05$ & $129.05 \pm 0.77$ \\
\hline SO1 & $275.3 \pm 2.52$ & $274.64 \pm 2.32$ & $10.7 \pm 1.09$ & $21.8 \pm 1.04$ & $129.44 \pm 3.04$ \\
\hline GB1 & $275.0 \pm 2.91$ & $247.54 \pm 4.44^{\mathrm{a}, \mathrm{b}}$ & $6.6 \pm 0.58^{b}$ & $7.6 \pm 0.6^{\mathrm{b}}$ & $129.84 \pm 5.54$ \\
\hline $\mathrm{CO} 2$ & $273.2 \pm 2.97$ & $273.29 \pm 2.98$ & $11.0 \pm 1.33$ & $22.3 \pm 1.23$ & $129.10 \pm 1.47$ \\
\hline $\mathrm{SO} 2$ & $275.8 \pm 4.06$ & $275.52 \pm 4.34$ & $10.8+1.13$ & $21.4 \pm 1.09$ & $128.84 \pm 2.27$ \\
\hline GB2 & $275.7 \pm 3.31$ & $244.54 \pm 3.48^{a, b}$ & $6.2 \pm 0.48^{\mathrm{b}}$ & $6.0 \pm 0.5^{\mathrm{b}}$ & $128.83 \pm 0.85$ \\
\hline
\end{tabular}

${ }^{\mathrm{a}} \mathrm{P}<0.01$ compared with the pre-operation group. ${ }^{\mathrm{b}} \mathrm{P}<0.01$ compared with the $\mathrm{CO}$ and $\mathrm{SO}$ groups, respectively. TNF $\alpha$, tumor necrosis factor $\alpha$; $\mathrm{CO}$, control; SO, sham operation.

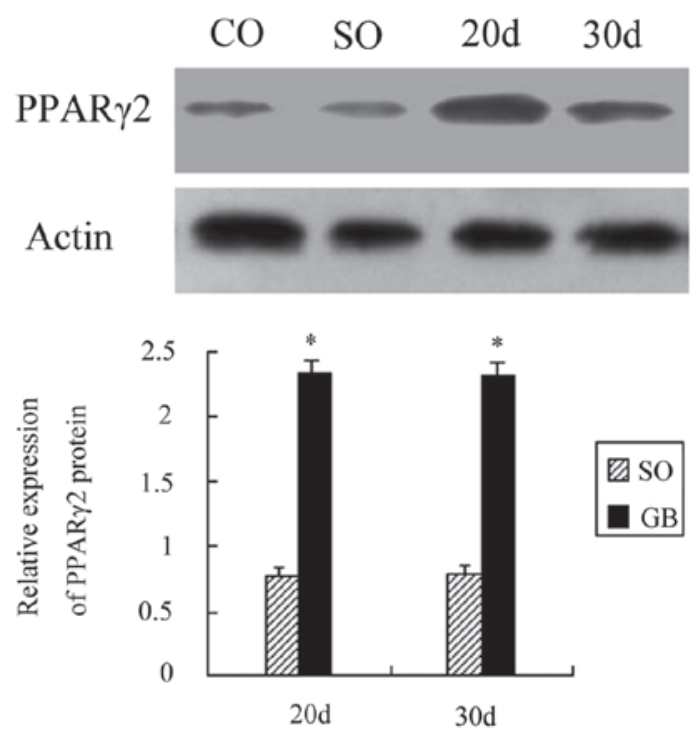

Figure 1. PPAR $\gamma 2$ protein expression after RYGB surgery. "P $<0.01$ when compared with the $\mathrm{CO}$ and $\mathrm{SO}$ groups after the same amount of time. PPAR $\gamma 2$, peroxisome proliferator-activated receptor $\gamma 2$; RYGB, Roux-en-Y gastric bypass; $\mathrm{CO}$, control; $\mathrm{SO}$, sham operation; $\mathrm{GB}$, gastric bypass.

expression was increased by 1.85 times and the difference was also statistically significant $(\mathrm{P}<0.01)$. PI $3 \mathrm{Kp} 85 \alpha$ mRNA expression between the $\mathrm{SO}$ and $\mathrm{CO}$ groups was not statistically significant $(\mathrm{P}>0.05)$. PI3Kp85a mRNA expression also showed no significant difference between the GB1 and GB2 groups ( $\mathrm{P}>0.05$; Fig. 3).

A total of 20 days after surgery, PI3Kp $85 \alpha$ protein expression was increased by 1.05 times as compared to the $\mathrm{CO}$ group and the difference was statistically significant $(\mathrm{P}<0.01)$. A total of 30 days after surgery, PI3Kp $85 \alpha$ protein expression was increased by 0.95 times and the difference was also statistically significant $(\mathrm{P}<0.01)$. $\mathrm{PI} 3 \mathrm{Kp} 85 \alpha$ protein expression between the $\mathrm{SO}$ and $\mathrm{CO}$ groups was not statistically significant $(\mathrm{P}>0.05)$. $\mathrm{PI} 3 \mathrm{Kp} 85 \alpha$ protein expression was also not significantly different between the GB1 and GB2 groups (P>0.05; Fig. 4).

The GLUT4 a mRNA, membrane protein and total protein expression increased following RYGB surgery. A total of 20

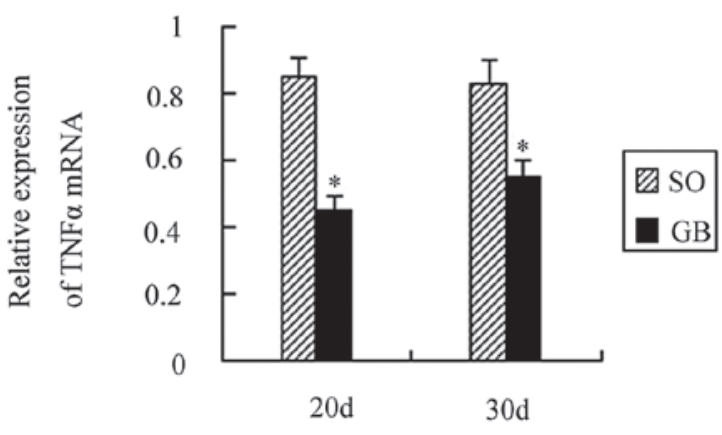

Figure 2. TNF $\alpha$ mRNA expression after RYGB surgery. ${ }^{*} \mathrm{P}<0.01$ when compared with the SO group after the same amount of time. TNF $\alpha$, tumor necrosis factor $\alpha$; RYGB, Roux-en-Y gastric bypass; SO, sham operation; GB, gastric bypass.

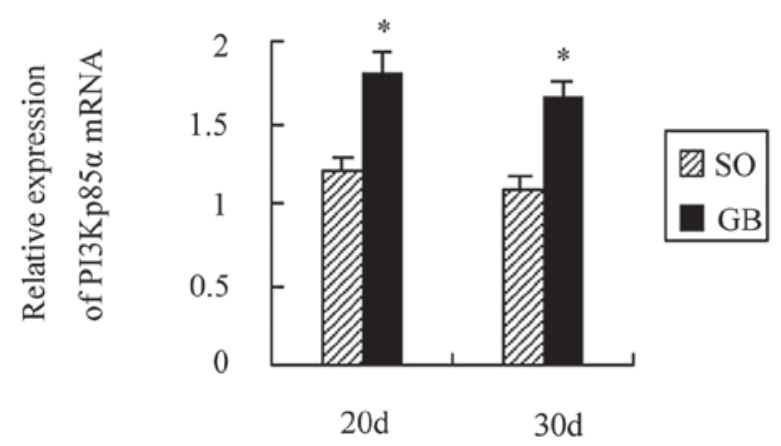

Figure 3. PI3Kp $85 \alpha$ mRNA expression after RYGB surgery. " $\mathrm{P}<0.01$ when compared with the SO group after the same amount of time. PI3Kp $85 \alpha$, phosphatidylinositol-3-kinase subunit p85a; RYGB, Roux-en-Y gastric bypass; $\mathrm{SO}$, sham operation; GB, gastric bypass.

days after surgery, GLUT4 $\alpha$ mRNA expression was increased by 1.24 times as compared to the $\mathrm{CO}$ group and the difference was statistically significant $(\mathrm{P}<0.01)$. A total of 30 days after surgery, GLUT4 $\alpha$ mRNA expression was increased by 1.29 times as compared to the $\mathrm{CO}$ group and the difference was also statistically significant $(\mathrm{P}<0.01)$. GLUT4 $\alpha$ mRNA expression between the $\mathrm{SO}$ and $\mathrm{CO}$ groups was not statistically significant $(P>0.05)$. GLUT4 $\alpha$ mRNA expression in the GB group was also not significant after 20 and 30 days (P>0.05; Fig. 5). 


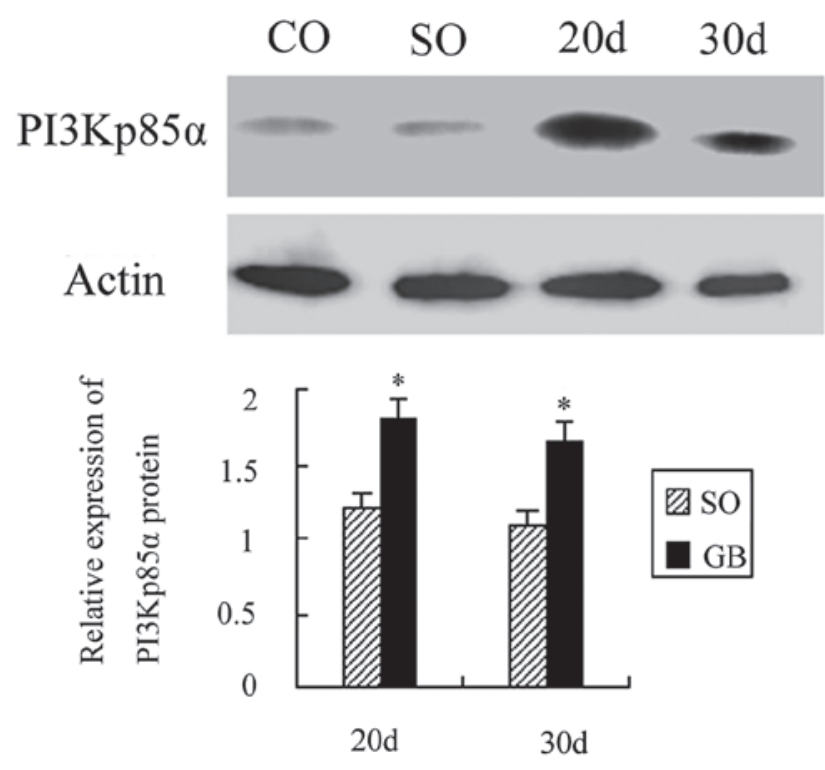

Figure 4. PI3Kp85 $\alpha$ protein expression after RYGB surgery. " $\mathrm{P}<0.05$ when compared with the $\mathrm{CO}$ and $\mathrm{SO}$ groups after the same amount of time. PI3Kp $85 \alpha$, phosphatidylinositol-3-kinase subunit p85 $\alpha$; RYGB, Roux-en-Y gastric bypass; $\mathrm{CO}$, control; $\mathrm{SO}$, sham operation; $\mathrm{GB}$, gastric bypass.

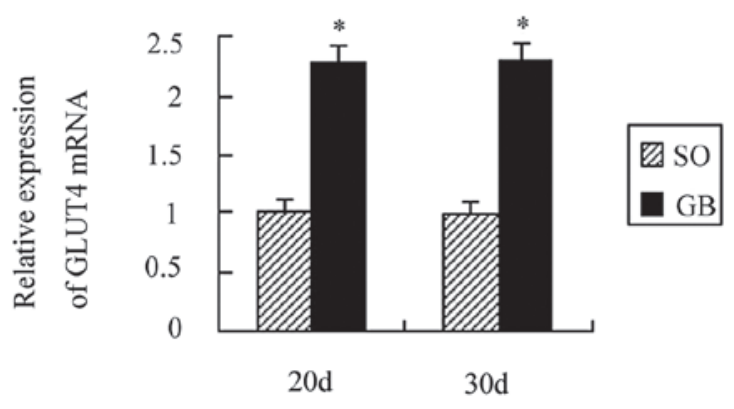

Figure 5. GLUT4 mRNA expression after RYGB surgery. ${ }^{*} \mathrm{P}<0.01$ when compared with the SO group after the same amount of time. GLUT4, glucose transporter 4; RYGB, Roux-en-Y gastric bypass; SO, sham operation; GB, gastric bypass.

A total of 20 days after surgery, the membrane GLUT4 protein expression was increased by 0.95 times as compared to the $\mathrm{CO}$ group and the difference was statistically significant $(\mathrm{P}<0.01)$. Thirty days after surgery, the membrane GLUT4 protein expression was increased by 0.80 times as compared to the $\mathrm{CO}$ group and the difference was also statistically significant $(\mathrm{P}<0.01)$. The membrane GLUT4 protein expression between the $\mathrm{SO}$ and $\mathrm{CO}$ groups was not statistically significant $(\mathrm{P}>0.05)$. The membrane GLUT4 protein expression in the GB group was also not significant after 20 and 30 days (P>0.05; Fig. 6).

A total of 20 days after surgery, the total GLUT4 protein expression was increased by 1.22 times as compared to the $\mathrm{CO}$ and SO groups and the difference was statistically significant $(\mathrm{P}<0.05)$. Thirty days after surgery, the total GLUT4 protein expression was increased by 1.35 times as compared to the $\mathrm{CO}$ and $\mathrm{SO}$ groups and the difference was also statistically significant $(\mathrm{P}<0.05)$. The total GLUT4 protein expression was not significant after 20 and 30 days $(\mathrm{P}>0.05$; Fig. 7).

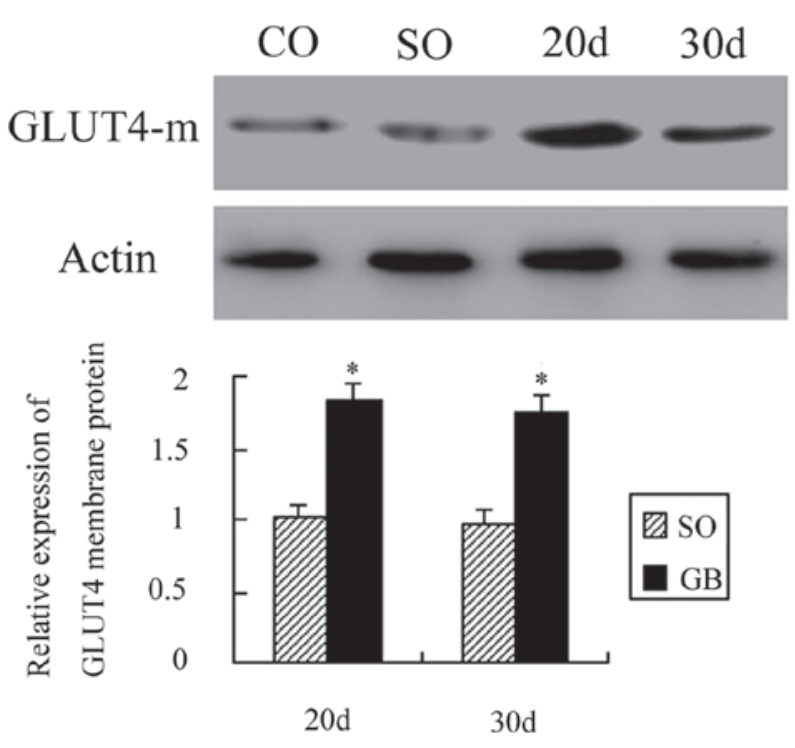

Figure 6. The membrane GLUT4 protein expression after RYGB surgery. ${ }^{*} \mathrm{P}<0.05$ when compared with the $\mathrm{CO}$ and $\mathrm{SO}$ groups after the same amount of time. GLUT4, glucose transporter 4; RYGB, Roux-en-Y gastric bypass; $\mathrm{CO}$, control; SO, sham operation; $\mathrm{GB}$, gastric bypass.

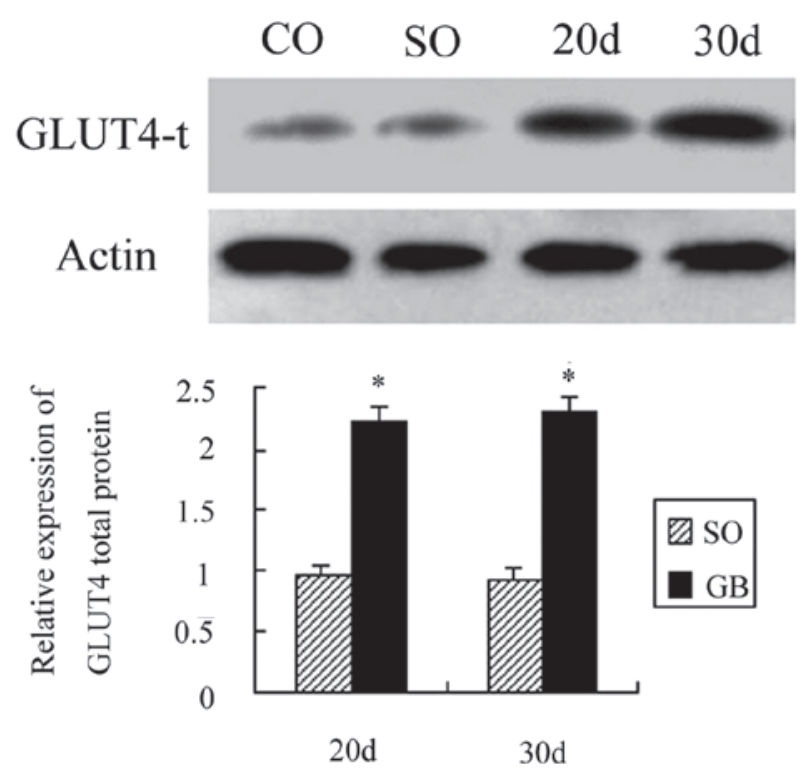

Figure 7. The total GLUT4 protein expression after RYGB surgery. " $\mathrm{P}<0.05$ when compared with the $\mathrm{CO}$ and $\mathrm{SO}$ groups after the same amount of time. GLUT4, glucose transporter 4; RYGB, Roux-en-Y gastric bypass; CO, control; SO, sham operation; GB, gastric bypass.

The correlation coefficient between fasting plasma glucose and GLUT4 protein was equal to 0.618 and $\mathrm{P}<0.01$. Fasting plasma glucose and GLUT4 protein were negatively correlated, and the difference was statistically significant.

\section{Discussion}

T2DM conventional treatment negatively impacts the patient's quality of life and requires long-term use of drugs. RYGB provides a new method of therapy for T2DM patients, which has changed the T2DM conventional treatment, improved patient 
quality of life and reduced the diabetes-related mortality (13). At present, increasing numbers of T2DM patients are selecting RYGB treatment (14). The possible mechanisms involved in RYGB are as follows: i) reducing food intake; ii) weight loss; iii) intestinal-insulin shaft mechanism. However, related studies indicated that dietary restrictions could not improve the blood glucose long-term. RYGB postoperative glucose was reduced earlier than weight loss, indicating that weight loss and reducing the food intake may not be the real cause of RYGB improving glucose levels. However, the exact mechanism involved remains unclear (15-18).

In our study, RYGB postoperative fasting blood glucose dropped to normal and the postprandial blood glucose decreased markedly as compared to the control group and sham operation group. It was confirmed that the RYGB not only reduced fasting blood glucose, but also reduced the postprandial blood glucose. Twenty and 30 days after surgery, TNF $\alpha$ mRNA expression was decreased and GLUT4 mRNA, PI3Kp85 $\alpha$, PPAR $\gamma 2$, and membrane and total GLUT4 protein expression were all elevated in postoperative adipose tissue. However, serum TNF $\alpha$ levels did not change significantly. Increased PPAR $\gamma 2$ may inhibit the expression of $\mathrm{TNF} \alpha$ mRNA, reduce TNF $\alpha$ expression in the fatty tissue, and not only increase PI3K expression through an autocrine manner and promote the translocation of GLUT4, but also increase the total GLUT4 protein in the fat cells, thereby improving insulin resistance $(19,20)$.

We suggest that increasing PPAR $\gamma 2$ protein, inhibiting TNF $\alpha$ transcription, upregulating PI3Kp $85 \alpha$ mRNA and protein, promoting GLUT4 protein translocation and upregulating total GLUT4 protein are the possible mechanisms by which RYGB improves insulin resistance and reduces fasting blood glucose in adipose tissue.

Adipose tissue is a target tissue of insulin action. Many fat factors are closely related to insulin resistance (21). PPAR $\gamma$ is specifically expressed in adipose tissue and the possible mechanism by which PPAR $\gamma$ improves insulin resistance may be as follows: i) PPAR $\gamma$ promotes fat cell differentiation. By this mechanism, activated PPAR $\gamma$ is capable of promoting white adipose cell differentiation and increasing the number of small fat cells and decreasing the number of large fat cells. Small fat cells respond more strongly to insulin and promote glucose uptake more easily. ii) PPAR $\gamma$ enhances the insulin signal transduction. PI3K is the key kinase that mediates transport of glucose into the target cells. The pathway, which is mediated by PI3K, is the main method of insulin signal transduction. The physiologically active PPAR $\gamma$ is capable of upregulating PI3Kp85 $\alpha$ expression and promoting signal transduction, thereby improving insulin resistance. iii) PPAR $\gamma$ inhibits the lipid metabolism. PPAR $\gamma$ is involved in the expression and regulation of related genes in lipid metabolism. Activated PPAR $\gamma$ may decrease fatty acids, which are transferred to the muscles and liver tissue. Adipose synthesis is then reduced, thereby improving insulin resistance.

$\mathrm{TNF} \alpha$ is an adipose factor that is secreted from adipose tissue to cause insulin resistance. The mechanism by which $\mathrm{TNF} \alpha$ affects adipose tissue insulin resistance may be as follows: i) TNF $\alpha$ inhibits tyrosine phosphorylation of insulin receptor substrate 1 , thereby inhibiting PI3K activity and impairing the insulin signaling pathway $(22,23)$; ii) $\mathrm{TNF} \alpha$ promotes the decomposition of fat cells and increases free fatty acids; iii) TNF $\alpha$ affects GLUT4 mRNA and protein expression (24-26); iv) $\mathrm{TNF} \alpha$ synergizes other cytokines $(7,10,27)$. In ob/ob mice and Zucker obese rats, TNF $\alpha$ mRNA is overexpressed and neutralizing $\mathrm{TNF} \alpha$ is capable of alleviating insulin resistance (28).

GLUT4 protein is the main effector molecule in insulinmediated glucose uptake and improving insulin resistance. Overexpression of GLUT4 protein may alleviate insulin resistance $(29,30)$. The animals with overexpression of GLUT4 protein may have improved glucose uptake and utilization, and this may significantly increase insulin sensitivity. Abel et al (31) selectively reduced the GLUT4 expression in fat cells by recombinant DNA technology and found that insulin-stimulated glucose uptake capacity reduced significantly in fat cells.

Our results showed that PPAR $\gamma$ expression was elevated following RYGB in adipose tissue and then TNF $\alpha$ mRNA transcription was reduced, while the serum $\mathrm{TNF} \alpha$ concentration was normal. The possible mechanism is that TNF $\alpha$ plays a role through a paracrine or autocrine method (31). While increasing the PI3Kp $85 \alpha$ expression, the switch of GLUT4 from vesicles to the cell membrane was increased. At the same time, reducing $\mathrm{TNF} \alpha$ content in adipose tissue may alleviate the inhibition effect on GLUT4 mRNA and increase the total GLUT4 content, thereby increasing glucose transport and insulin sensitivity.

In short, RYGB may improve insulin resistance and treat type 2 diabetes through upregulation of PPAR $\gamma 2$ protein, downregulation of TNF $\alpha$ mRNA transcription, upregulation of PI3Kp $85 \alpha$ expression, induction of the translocation of GLUT4, upregulation of GLUT4 mRNA transcripts and increased total GLUT4 content in adipose tissue. However, the mechanism by which PPAR $\gamma 2$ protein is upregulated requires further study.

\section{References}

1. Yang W, Lu J, Weng J, et al: Prevalence of diabetes among men and women in China. N Engl J Med 362: 1090-1101, 2010.

2. Zimmet P, Alberti KG and Shaw J: Global and societal implications of the diabetes epidemic. Nature 414: 782-787, 2001.

3. Couzin J: Medicine. Bypassing medicine to treat diabetes. Science 320: 438-440, 2008.

4. Lazar MA: How obesity causes diabetes: not a tall tale. Science 307: 373-375, 2005.

5. Kadowaki T, Hara K, Kubota N, et al: The role of PPARgamma in high-fat diet-induced obesity and insulin resistance. J Diabetes Complications 16: 41-45, 2002.

6. Mishima Y, Kuyama A, Tada A, Takahashi K, Ishioka T and Kibata M: Relationship between serum tumor necrosis factoralpha and insulin resistance in obese men with Type 2 diabetes mellitus. Diabetes Res Clin Pract 52: 119-123, 2001.

7. Ruan H and Lodish HF: Insulin resistance in adipose tissue: direct and indirect effects of tumor necrosis factor-alpha. Cytokine Growth Factor Rev 14: 447-455, 2003.

8. Murakami K, Bujo H, Unoki H and Saito Y: High fat intake induces a population of adipocytes to co-express TLR2 and TNFalpha in mice with insulin resistance. Biochem Biophys Res Commun 354: 727-734, 2007

9. Chen H, Ren A, Hu S, Mo W, Xin X and Jia W: The significance of tumor necrosis factor-alpha in newly diagnosed type 2 diabetic patients by transient intensive insulin treatment. Diabetes Res Clin Pract 75: 327-332, 2007.

10. Li L, Yang G, Shi S, Yang M, Liu H and Boden G: The adipose triglyceride lipase, adiponectin and visfatin are downregulated by tumor necrosis factor-alpha (TNF-alpha) in vivo. Cytokine 45: 12-19, 2009. 
11. Garvey WT, Maianu L, Huecksteadt TP, Birnbaum MJ, Molina JM and Ciaraldi TP: Pretranslational suppression of a glucose transporter protein causes insulin resistance in adipocytes from patients with non-insulin-dependent diabetes mellitus and obesity. J Clin Invest 87: 1072-1081, 1991.

12. Zisman A, Peroni OD, Abel ED, et al: Targeted disruption of the glucose transporter 4 selectively in muscle causes insulin resistance and glucose intolerance. Nat Med 6: 924-928, 2000.

13. Adams TD, Gress RE, Smith SC, et al: Long-term mortality after gastric bypass surgery. N Engl J Med 357: 753-761, 2007.

14. Buchwald $\mathrm{H}$ and Oien DM: Metabolic/bariatric surgery Worldwide 2008. Obes Surg 19: 1605-1611, 2009.

15. Laville $M$ and Disse E: Bariatric surgery for diabetes treatment: why should we go rapidly to surgery. Diabetes Metab 35: 562-563, 2009.

16. Mingrone G and Castagneto-Gissey L: Mechanisms of early improvement/resolution of type 2 diabetes after bariatric surgery. Diabetes Metab 35: 518-523, 2009.

17. Scheen AJ, De Flines J, De Roover A and Paquot N: Bariatric surgery in patients with type 2 diabetes: benefits, risks, indications and perspectives. Diabetes Metab 35: 537-543, 2009.

18. Andreelli F, Amouyal C, Magnan C and Mithieux G: What can bariatric surgery teach us about the pathophysiology of type 2 diabetes? Diabetes Metab 35: 499-507, 2009

19. Rieusset J, Chambrier C, Bouzakri K, et al: The expression of the p85alpha subunit of phosphatidylinositol 3-kinase is induced by activation of the peroxisome proliferator-activated receptor gamma in human adipocytes. Diabetologia 44: 544-554, 2001.

20. Iwata M, Haruta T, Usui I, et al: Pioglitazone ameliorates tumor necrosis factor-alpha-induced insulin resistance by a mechanism independent of adipogenic activity of peroxisome proliferator-activated receptor-gamma. Diabetes 50: 1083-1092, 2001.

21. Antuna-Puente B, Feve B, Fellahi S and Bastard JP: Adipokines: the missing link between insulin resistance and obesity. Diabetes Metab 34: 2-11, 2008.

22. Hotamisligil GS, Budavari A, Murray D and Spiegelman BM: Reduced tyrosine kinase activity of the insulin receptor in obesity-diabetes. Central role of tumor necrosis factor-alpha. J Clin Invest 94: 1543-1549, 1994.
23. Hotamisligil GS, Peraldi P, Budavari A, Ellis R, White MF and Spiegelman BM: IRS-1-mediated inhibition of insulin receptor tyrosine kinase activity in TNF-alpha- and obesity-induced insulin resistance. Science 271: 665-668, 1996.

24. Stephens JM and Pekala PH: Transcriptional repression of the C/EBP-alpha and GLUT4 genes in 3T3-L1 adipocytes by tumor necrosis factor-alpha. Regulations is coordinate and independent of protein synthesis. J Biol Chem 267: 13580-13584, 1992.

25. Fernandez-Veledo S, Hernandez R, Teruel T, Mas JA, Ros M and Lorenzo M: Ceramide mediates TNF-alpha-induced insulin resistance on GLUT4 gene expression in brown adipocytes. Arch Physiol Biochem 112: 13-22, 2006.

26. Mingrone G, Rosa G, Di Rocco P, et al: Skeletal muscle triglycerides lowering is associated with net improvement of insulin sensitivity, TNF-alpha reduction and GLUT4 expression enhancement. Int J Obes Relat Metab Disord 26: 1165-1172, 2002.

27. Chung S, Lapoint K, Martinez K, Kennedy A, Boysen Sandberg M and McIntosh MK: Preadipocytes mediate lipopolysaccharideinduced inflammation and insulin resistance in primary cultures of newly differentiated human adipocytes. Endocrinology 147: 5340-5351, 2006.

28. Hotamisligil GS, Shargill NS and Spiegelman BM: Adipose expression of tumor necrosis factor-alpha: direct role in obesitylinked insulin resistance. Science 259: 87-91, 1993.

29. Carvalho E, Kotani K, Peroni OD and Kahn BB: Adiposespecific overexpression of GLUT4 reverses insulin resistance and diabetes in mice lacking GLUT4 selectively in muscle. Am J Physiol Endocrinol Metab 289: E551-561, 2005.

30. Brozinick JT Jr, McCoid SC, Reynolds TH, et al: GLUT4 overexpression in $\mathrm{db} / \mathrm{db}$ mice dose-dependently ameliorates diabetes but is not a lifelong cure. Diabetes 50: 593-600, 2001.

31. Abel ED, Peroni O, Kim JK, et al: Adipose-selective targeting of the GLUT4 gene impairs insulin action in muscle and liver. Nature 409: 729-733, 2001. 